\title{
A literatura cigana e a e as tecnologias de si: Uma interpretação possivel
}

\author{
Lorena Oliveira Tavares (UNEB) \\ Orcid: https://orcid.org/0000-0001-8123-7402 \\ Luciana Sacramento Moreno Gonçalves (UNEB) \\ Orcid: https://orcid.org/0000-0001-7742-0829
}

\section{Resumo:}

Este artigo se propõe a fazer uma breve análise do livro "El aliento negro de los romaníes", de Jorge Nedich (2005), a partir das reflexões de autores que discutem o retorno do autor e a virada etnográfica. 0 que levou ao desenvolvimento desta produção foram as discussões em torno dos fundamentos da linguagem na tradição metafísica ocidental, considerando a problematização dos paradigmas da interpretação e das tecnologias de si, tendo o sujeito como o início da produção discursiva. 0 objetivo geral deste estudo é levantar na aludida obra literária os traços do povo rom (cigano) a partir da escrita de Jorge Nedich e da interpretação das pesquisadoras com base em estudiosos que discutem o tema. Dentre os autores que influenciaram e deram suporte teórico para realização deste estudo, destacam-se Foucault (1992), Klinger (2012) e Sória (2015). Os resultados apontaram para o fato de que é impossível se despir completamente de seus valores para se olhar o objeto de estudo, neste caso, o romance de Jorge Nedich, e que não há uma receita ou fórmula que assegure uma interpretação ideal, esperada pelo autor da obra; chegando-se a uma interpretação real, que é feita pelo leitor.

Palavras chave: Cultura romà; Literatura cigana; Escrita de si, Virada etnográfica.

\section{Abstract:}

\section{Roma literature and the technologies of themselves: A possible interpretation}

This article proposes to make a brief analysis of the book "El Aliento negro de los romaníes", by Jorge Nedich (2005), from the reflections of authors who discuss the author's ethnographic turn. What led to the development of this production were the discussions around the fundamentals of language in

* Doutora em Letras pela Pontifícia Universidade Católica do Rio Grande do Sul - PUC-RS. Professora Adjunta da Universidade do Estado da Bahia - UNEB. Professora Permanente no Programa de Pós-Graduação em Estudo de Linguagens - PPGEL/UNEB. E-mail: lusamog@gmail.com

** Mestranda em Estudo de Linguagens (UNEB - PPGEL). Mestre em Educação (UNIEUBRA). Professora Auxiliar, UNEB. Coordenadora do Curso de Extensão em Língua Espanhola Avançada (NUPE-PROEX-UNEB). E-mail: loren.tavares@hotmail.com 
the Western metaphysical tradition, considering the problematization of the paradigms of interpretation and the technologies of oneself, having the subject as the beginning of discursive production. The general objective of this study is to raise in the alluded literary work the traces of the rom people (gypsy) from the writing of Jorge Nedich and the interpretation of the researcher based on scholars who discuss the theme. Among the authors who influenced and gave theoretical support for this study, we highlight Foucault (1992), Klinger (2012) and Sória (2015).The results pointed to the fact that it is impossible to completely undress from their values to look at the object of study, in this case, the novel by Jorge Nedich, as well as there is no recipe or formula that ensures an ideal interpretation, the expected by the author of work arriving at a real interpretation, which is made by each reader.

Keywords: Culture romà; Gypsy literature; Writing fram you; Ethnographic turn.

\section{Introdução}

O objetivo deste artigo é fazer uma análise sucinta do livro "El aliento negro de los romaníes", de Jorge Nedich, à luz de algumas considerações acerca das teorias do retorno do autor e da virada etnográfica. 0 que levou ao desenvolvimento desta análise foram as reflexões sobre as relações entre as diversas concepções de linguagem e as práticas discursivas nelas envolvidas, considerando a problematização da interpretação, bem como o entendimento da subjetividade como produção.

Assim sendo, as pesquisadoras investiram em leituras e discussões que conversassem com o sistema de interpretação na hermenêutica moderna, partindo do sujeito como produção discursiva a fim de estabelecer um diálogo profícuo com a obra e o autor ora em análise.

Antes de proceder à teoria, se faz necessário contextualizar o leitor acerca de Jorge Nedich e do livro "El aliento negro de los romaníes". 0 autor de origem rom $^{1}$, nasceu em

1 "Rom" significa "cigano" na língua romaní. No presente artigo os "ciganos" sempre serão chamados de "romà" devido à nova denominação étnica defendida por eles; já que o termo "ciganos" está ligado ao preconceito e discriminação, além
Sarnadí, zona sul de Buenos Aires, Argentina, em 1959 - e viveu como nômade até os 17 anos. Ingressou várias vezes na escola primária, mas não dava continuidade aos estudos, pois nunca chegava a passar seis anos em um mesmo local. Desde muito pequeno vendia naftalina, agulha e outras miudezas pelas ruas, além de lustrar sapatos. Nas palavras dele, fez "tudo o que faz uma família cigana que está em uma situação de marginalidade" (Em entrevista ao jornal Tiempo Argentino, tradução nossa). ${ }^{2}$ Ainda segundo Nedich, eram muito pobres, motivo pelo qual ele diz que já vendia desde o ventre de sua mãe, já que ela se dedicava a esse ofício quando estava grávida dele. Aprendeu a ler nas histórias das revistas antigas que vendia nos trens. Já adulto, com 39 anos, com a Lei Duhalde (que dava direito a pessoas que não haviam frequentado a escola fazerem uma

de haver sido uma denominação dada pelos não ciganos.

2 "[...] todo lo que hace una familia gitana que está en una situación de marginalidad" (En entrevista al Periódico Tiempo Argentino. Disponível em: https://www.tiempoar.com.ar/nota/jorgenedich-los-gitanos-aun-no-somos-sujetos-dederecho). 
prova para ingressarem na universidade), foi aprovado na Universidad Nacional de Lomas de Zamora. Após um ano e alguns meses de ter iniciado o Curso de Letras, acabou finalista do Prêmio Planeta, em 1999, com o romance "Leyenda gitana", publicado no ano de 2000. Mas essa não foi a sua primeira publicação. Já havia publicado "Gitanos, para su bien o para su mal" (1994) e "Ursari" (1997). Em 2014, com 13 livros publicados (traduzidos para o português, romaní e italiano), fundou sua própria editora "Voria Stevanofsky", através da qual reeditou " $E l$ aliento negro de los romaníes", romance que foi finalista do Prêmio Planeta em 2004 e foi particularmente elogiado pelo presidente do juri, Héctor Tizón.

Aqui é utilizada a publicação de 2005 do romance "El aliento negro de los romaníes", obra contemporânea que conta a história de Petre e sua esposa Maida que, por não poder seguir com sua vida de nômades, acabam ficando muito tempo em um povoado e criando vínculos com os não romà, chegando a apaixonarem-se por pessoas que fazem parte deste mundo.

\section{Tecnologias de si: um panorama}

Ao tomar o romance nas mãos, o leitor pode pensar que por ser um romà seu escritor, encontraria uma narrativa em que exaltaria o seu povo, expressando suas qualidades e construindo um estereótipo sobre o outro culturalmente afastado, contudo, não é isso que acontece. No decorrer das páginas $\mathrm{Ne}$ dich constrói a narrativa mostrando a complexidade dos diferentes povos, sobretudo dos romà.

E, por o romance possuir fortes marcas autobiográficas, ao trazer situações que aconteceram na vida do autor, a exemplo das dificuldades financeiras e do fato deste ter tido suas barracas queimadas, atravessa as fronteiras culturais dos dois povos, já que o autor vive numa espécie de "entremundo", transitando nos dois universos, dos romà e não-romà, mas não necessariamente pertencendo integralmente a nenhum deles. Assim, nessa ficção confluem duas perspectivas, a escrita de si e a escrita do outro, identificando-se assim duas tendências: o retorno do autor e a virada etnográfica, pois o traço marcante da presença autobiográfica real do autor empírico se mistura ao ficcional de maneira a situar o discurso na interface entre o real e o ficcional.

Klinger (2012) utiliza a definição de Philippe Lejeune (1996) para afirmar que

O que diferencia a ficção da autobiografia não é a relação que existe entre os acontecimentos da vida e sua transcrição no texto, mas o pacto implícito ou explícito que o autor estabelece com o leitor, através de vários indicadores presentes na publicação do texto, que determina seu modo de leitura (KLINGER, 2012, p.10).

Ou seja, para considerar um texto como autobiografia depende-se muito mais do pacto estabelecido, seja ele ficcional ou referencial. Partindo desse princípio, considerase "El aliento negro de los romaníes" como uma narrativa que se encaixa no "entrelugar", porque a partir de uma história ficcional, Nedich (2005) relata fatos que aconteceram em sua vida quando ainda vivia como nômade e traz à tona elementos da cultura romà que são reais, e que só sendo um deles para abordar tantos detalhes de modo tão espontâneo e natural. Assim, ele transgride de alguma forma o pacto ficcional, pois incorpora elementos que exigem serem lidos através do viés referencial, principalmente porque nas entrevistas feitas ao autor sobre o romance, ele faz questão de salientar essa relação, como mostra este trecho do jornal Tiempo Argentino: "Neste romance se ficcio- 
nalizam alguns elementos tomados da própria vida do autor e da de seus ancestrais que chegaram à Argentina desde a Romênia em 1870, logo após haverem sido liberados da escravidão a que foram submetidos entre 1380 y 1868" (López Ocón, 2018, tradução nossa $)^{3}$.

Ainda tomando como base o conceito de Philippe Lejeune, Klinger (2012) explica que "o espaço autobiográfico compreende o conjunto de todos os dados que circulam ao redor da figura do autor: suas memórias e biografias, seus (auto) retratos e suas declarações sobre sua própria obra ficcional" (Klinger, 2012, p.10). Assim sendo, o autor acaba revelando muito de si e de sua vida, possuindo traços que se investigados mais detidamente podem inclusive ser comprovados, como é o caso da queima das barracas retratadas no romance:

Durante o sono, o calor dos colchões de pena de ganso se fez mais intenso, muito intenso, como um inferno. Logo, uma gritaria ensurdecedora o despertou em alerta: ante seus olhos tudo ardia como na época da Santa Inquisição. Ardia a mesa com sua bola de cristal, a seguinte com a borra de café; as cartas se incineraram com o destino escrito, as figuras bíblicas, essa noite os fantasmas temerosos se esconderam do fogo, o campo milagroso ardia sem compaixão (NEDICH, 2005, p.70, tradução nossa). ${ }^{4}$

3 En esta novela se ficcionalizan algunos elementos tomados de la propia vida del autor y la de sus ancestros que llegaron a la Argentina desde Rumania en 1870, luego de ser liberados de la esclavitud a que fueron sometidos entre $1380 \mathrm{y}$ 1868 (LÓPEZ OCÓN, 2018, Periódico Tiempo Argentino. Disponível em: https://www.tiempoar. com.ar/nota/jorge-nedich-los-gitanos-aun-nosomos-sujetos-de-derecho).

4 Durante el sueño, la tibieza de los colchones de pluma de ganso se hizo calor intenso, muy intenso, como un infierno. Luego un griterío ensordecedor lo despertó en vilo: ante sus ojos todo ardía como en la época de la Santa Inquisición. Ardía la mesa con su bola de cristal, la siguiente
0 trecho faz referência ao que aconteceu na Argentina dos anos de 1946, pouco depois da Segunda Guerra Mundial, onde morreram "[...] segundo as estimativas mais conservadoras, entre $220 \mathrm{mil} \mathrm{e} 500 \mathrm{mil} \mathrm{ci}$ ganos. Estimativas posteriores dizem que foram 1.500.000. Qualquer que seja a cifra, foram muitos os ciganos que morreram. A política de perseguição e extermínio do povo cigano reinava em todo o mundo, não somente na Argentina" (López Ocón, 2018, tradução nossa $)^{5}$.

E este foi um fato que foi sentido diretamente pela família de Nedich. Ele relata em entrevista ao jornal Tiempo Argentino que seu bisavô Bobia estava em uma dessas barracas e que teria se negado a sair da sua. Então, atearam fogo com ele dentro, o que o levou a morte. Segundo Nedich, isso afetou muito o seu avô, de modo que quando Perón voltou ao governo, em 1973, seu avô teve um infarto, pois tinha medo que voltassem às perseguições e mais alguém da sua família morresse. Nesta entrevista, Nedich conta também que em seu primeiro mandato, Perón exigiu que os romà vivessem em casas e que se desfizessem de suas vestimentas típicas, bem como de sua língua. Os que puderam comprar uma casa, o fizeram, outros, se mudaram da província, e muitos nem

con la borra de café; se incineraron las cartas con el destino escrito, las figuras bíblicas, esa noche los fantasmas temerosos se escondieron del fuego, el campo milagroso ardía sin compasión (NEDICH, 2005, p.70).

5 “[...] según las estimaciones más conservadoras, entre 220 mil y 500 mil gitanos. Estimaciones posteriores dicen que fueron 1.500.000. Cualquiera sea la cifra, fueron muchos los gitanos que murieron. La política de persecución y exterminio del pueblo gitano reinaba en todo el mundo, no sólo en la Argentina." (LÓPEZ OCÓN, 2018, Periódico Tiempo Argentino. Disponível em: https://www.tiempoar.com.ar/nota/jorgenedich-los-gitanos-aun-no-somos-sujetos-dederecho). 
souberam do que acontecia porque estavam afastados da capital, onde se exigia a execução das medidas. De acordo com Nedich, seu avô Tete, o filho do citado Bobia, comprou um terreno e começou a construir uma casa; mas seu terror era tanto que mesmo dentro da casa não permitia que nenhum dos seus se vestissem como romà, todos tinham que ficar disfarçados de não-romà.

Nesta época havia muitos romà ocupando a região que hoje é conhecida como " $L a$ Recoleta" e "Plaza Houssay", da qual foram expulsos. Tais políticas continuaram nos anos 60 porque foram os militares quem as implementou. Neste período Nedich diz que sua mãe e irmã foram presas porque a mendicância estava proibida, no entanto, segundo ele, elas nem estavam mendigando, estavam vendendo. Sua mãe foi posta na cadeia e sua irmã colocada em um orfanato, de onde só saíram após pagarem um advogado para tirá-las de lá. Queriam colocar sua irmã para a adoção pois, de acordo com os governantes, não era justo que uma criança tivesse que vender nas ruas para sobreviver; como acontece muito ainda hoje em vários países europeus. A Itália é um exemplo, onde as crianças são tiradas dos romà e colocadas para adoção sem a permissão de seus pais (López Ocón, 2018).

$\mathrm{Na}$ referida entrevista ao jornal Tiempo Argentino, Nedich diz que quando mulheres romà vão ao hospital, muitas vezes são esterilizadas sem consentimento a fim de não seguirem procriando, ou seja, os Direitos Humanos, em muitos lugares no mundo, não são aplicados aos romà. Nas palavras de Nedich: "Ainda não somos sujeitos de direito" 6 .

A partir do exposto fica clara a relação

6 “Todavía no somos sujetos de derechos" (LÓPEZ OCÓN, 2018, Periódico Tiempo Argentino. Disponível em: https://www.tiempoar.com.ar/ nota/jorge-nedich-los-gitanos-aun-no-somossujetos-de-derecho). dos fatos narrados com a vida do autor, bem como suas declarações, que só ratificam a teoria do retorno do autor. E talvez seja essa transgressão do "pacto ficcional", embora continue sendo uma "ficção" que torne o seu texto tão instigante, sendo ao mesmo tempo ficcional e (auto) referencial. Assim, Nedich problematiza a ideia de referência e incita a abandonar o rígido binarismo entre fato e ficção.

Por outro lado, ele também dá conta de um movimento narrativo atual que, segundo Klinger (2012) "é uma das faces da literatura latino-americana pós-ditaduras no Cone Sul", havendo "[...] na ficção recente, uma atração pelas figuras marginais da sociedade que expõem o dilema acerca da representação da outridade" (Klinger, 2012, p.11). Esse movimento se consolidou, principalmente no âmbito dos estudos culturais, a partir da década de 60 - momento em que houve uma tomada de consciência das classes marginalizadas e começaram a reivindicar representação nas diversas áreas, como política, cultural, artística e literária.

Ao narrar outras vozes que não somente a dos romà, Nedich acaba buscando dar conta da distância dele mesmo em relação ao seu povo, e ao mesmo tempo, assumindo-se como "tradutor" dos romà em relação ao mundo exterior. Isso só é possível devido ao seu livre-trânsito entre as duas culturas, pertencendo a um "entrelugar", como denomina Sória (2015), que o possibilita dar conta da multiplicidade das linguagens que circulam na sociedade à qual faz parte, sendo ele mesmo a figura mediadora dos dois mundos.

De acordo com Sória (2015), Nedich não é o único escritor romà contemporâneo que vive esta situação. São vários os que vivem neste "entrelugar" por negociarem seu pertencimento aos romà e à cultura majoritá- 
ria, o que os torna indivíduos "híbridos", visto que, mesmo sendo descendentes diretos de romà, desempenham profissões diferentes daquelas comuns ao grupo, o que causa cisões dentro de alguns grupos, sobretudo entre os mais tradicionais.

A atração pelas figuras marginais e o dilema da representação da outridade excede o campo das artes, transformando a literatura de tal modo que gerou uma virada etnográfica, o que implica em uma "transfronteirização" do conhecimento, para usar o termo de Klinger (2012), a partir da problemática da cultura. Assim sendo, "com a ampla difusão dos estudos culturais, as fronteiras entre disciplinas humanísticas foram se enfraquecendo, de maneira que, [...] aconteceu uma 'antropologização' do campo intelectual” (Klinger, 2012, p.12). 0 que é bem fácil de perceber até mesmo ao ler estas páginas, pois muitas das informações trazidas num estudo como este partem do âmbito antropológico, aproximando-se dessa forma dos estudos da antropologia pós-moderna, que pressupõe um "retorno do autor", narrando experiências subjetivas de choque cultural, tendo como ponto de partida Geertz (1973).

De acordo com Klinger (2012), "no mesmo paradigma epistemológico da antropologia pós-moderna se inscreve certa crítica contemporânea, que valoriza a experiência da leitura e o ato da escrita" (Klinger, 2012, p.13), que é o que se está fazendo neste estudo sobre os romà nesta obra de Nedich (2005). E isso acontece no ponto de confluência entre uma tendência literária e uma epistemológica.

\section{Nedich e Foucault: Um Diálogo Proficuo}

O narrador começa o romance com a ideia da vida como devir e uma transformação crucial, características do relato autobio- gráfico: "Outras vezes, Petre mudava de pensamento e seus olhos pareciam contemplar coisas invisíveis com ar assombrado, se imaginava orgulhoso adestrando o urso [...]. Petre sabia que faltava muito para que seu sonho se cumprisse, mas não podia deixar de se preparar" (Nedich, 2005, p.16 e 17, tradução nossa $)^{7}$.

Embora o texto não esteja em primeira pessoa, o narrador pressupõe uma mudança interna, uma transformação radical que impulsiona o personagem principal, pois no momento em que Petre resolve comprar o urso e faz planos de confeccionar trinta mil utensílios de cobre para conseguir tal intento, ele acaba por decidir ficar no povoado mais tempo que o normal para um romà, pois para os romà “[...] não era bom isto de estar quietos e colocar a terra para parir para ele; que classe de rom era que não andava percorrendo o mundo?" (Nedich, 2005, p.37, tradução nossa $)^{8}$. Assim sendo, ele passaria a ser um sedentário, modo que eles se referem aos não-romà, principalmente pelo fato de "[...] fazer a terra parir em seu benefício até tirar-lhe o ar ou sugar-lhe tudo" [...] (Nedich, 2005, p.15, tradução nossa) ${ }^{9}$. 0 que seria, na época em que a narrativa é contada, uma contravenção à "norma" cultural dos romà, e também nos dias de hoje para os grupos que são mais rígidos em torno dos costumes.

7 Otras veces, Petre cambiaba de pensamientos y sus ojos parecían contemplar cosas invisibles con aire asombrado, se imaginaba orgulloso amaestrando al oso [...]. Petre sabía que faltaba mucho para que su sueño se cumpliera, pero no podía dejar de prepararse (NEDICH, 2005, p.16 e 17).

$8[. .$.$] no era bueno esto de estarse quieto y poner$ a la tierra a parir para él; qué clase de rom era que no andaba recorriendo el mundo (NEDICH, 2005, p.37).

9 [...] hacer parir a la tierra en su beneficio hasta quitarle el aliento [...] (NEDICH, 2005, p.15). 
Outro fator que chama a atenção é que vários dos elementos do livro identificam os personagens com o autor, como já mencionado anteriormente, evocando situações que o próprio Nedich faz questão de contar sempre que dá uma entrevista, como haver sido nômade e hoje ser sedentário. Tal conduta leva ao questionamento: Será que o intuito dessas relações de sua vida com a ficção seria marcar sua singularidade no mundo? Uma possibilidade para esta questão é apresentar-se como alguém que tem a vida envolta em uma história que beira o romanesco, colocando-se num lugar de destaque, pois teria algo de sua vida que é especial e por isso merece ser contada.

A maneira como Nedich escreve, fugindo de uma idealização dos romà como exóticos, colocando-os no lugar de pessoas comuns, que precisam trabalhar para sobreviver e têm necessidades fisiológicas como todo mundo oferece o inesperado, ao narrar trechos que ao mesmo tempo em que humanizam os romà, explicitam de forma contundente aspectos muitas vezes camuflados no texto literário:

Esta manhã, antes de levantar-se, totalmente despreocupado sobre a cama, sua mão havia feito um ou dois movimentos sobre seu pênis, que foram além do toque distraído, a consequência foi que um espírito quente e viscoso saísse como um dardo de seu pau; realmente havia sido um bom disparo, a mais de um metro chegou o salto (NEDICH, 2005, p.152, tradução nossa). ${ }^{10}$

Este tipo de relato problematiza a noção de identidade da própria voz narrativa, pois

10 Esa mañana antes de levantarse, había estado tirado a la bartola sobre la cama, su mano había hecho uno o dos movimientos sobre su pene que fueron más allá de la sobada distraída, la consecuencia fue que un espíritu caliente y gomoso salió como un dardo de su cerbatana; realmente había sido un buen disparo, a más de un metro llegó el salto (Nedich, 2005, p.152).
Nedich escreve de forma que se aproxima tanto de períodos literários como o naturalista quanto de um neorrealismo contemporâneo, ao descrever minunciosamente aspectos fisiológicos de forma direta, explícita, sem pudores. 0 que foi considerado pelos críticos literários do final do século XIX, no Brasil, como uma má assimilação do modelo naturalista francês.

Então, em sua urgência em se relacionar com a realidade histórica e ao mesmo tempo com a atualidade, ele descreve determinadas cenas de uma maneira tão realista que chega a surpreender o leitor. Nas páginas deste artigo pensa-se na intenção dele (Nedich) e no paradoxo de estar-se utilizando este livro como corpus de um estudo que busca discutir questões de preconceito e discriminação, quando, ao ler esses trechos no livro em comento, as pesquisadoras são tomadas de um sobressalto e se perguntam se elas, também, não teriam romantizado os rom por haverem lido tantos textos que estereotipam, via romantização sua posição no mundo e autores como Lorca ${ }^{11}$, que chega a colocá-los num lugar destacado, definindo-os, segundo Caballero e Josephs (1995), como artistas que só podem incluirse na categoria de Goya ${ }^{12}$, e acrescenta que escolhe os romà "[...] porque os considera o mais elevado, profundo e aristocrático da Espanha. Acredita que eles são o mais representativo da Andaluzia e do universal" (Caballero e Josephs, 1995, p. 105 e 106, tradução nossa $)^{13}$.

Interessante ressaltar que Caballero e Josephs (1995) fazem questão de salientar

11 Poeta e dramaturgo espanhol, é o escritor mais famoso desta nacionalidade do século XX.

12 Francisco José de Goya y Lucientes foi um renomado pintor espanhol.

13 [...] porque los considera lo más elevado, profundo y aristocrático de España. Creyéndolos lo más representativo de Andalucía y de lo universal. Caballero y Josephs (1995, p.105-106). 
que Lorca não precisou imaginar nada do que escreveu em seu livro de poemas " $R o$ mancero Gitano", porque havia vivido entre os romà, pois seu pai gostava de se reunir com eles após o trabalho para cantar, tocar e conversar; assim teria conhecido de perto as características dos futuros protagonistas de sua obra. No entanto, vale ressaltar que conhecer os romà é diferente de ser um deles, vez que passar um tempo entre eles não leva o sujeito necessariamente a ver o mundo e senti-lo como um romà, como é o caso de Nedich, autor da obra em análise.

Por essa razão, pensa-se se ao escrever "El aliento negro de los romaníes", o enunciado não entra em contradição com o enunciador (Nedich), no sentido dos romà escreverem, principalmente, segundo Sória (2015), com o fito de oferecer às sociedades circundantes uma visão de mundo a partir da perspectiva "de dentro", ou seja, visam contribuir na subversão dos discursos preconceituosos, desmistificando os estereótipos. Contudo, com os trechos que se seguem, (entre outros que não serão transcritos, vez que julga-se suficientes os exemplos abaixo) fica o questionamento se não aconteceria justo o contrário com o leitor leigo:

[...] Metido na noite de seu chapéu dormiu junto a Carlo e o burro no estábulo; os três tinham o mesmo aroma [...] / [...] Petre cuspiu na mão e ajeitou o cabelo [...] / [...] enquanto evacuava seu estômago, inclinou um pouco o pescoço para baixo para afinar o ouvido e assim poder escutar com fidelidade o som de suas fezes caindo na terra [...] / [...] Lucía, depois dos primeiros jatos, começou a edificar um monte de bom tamanho, entre amarelo e mostarda. [...] Stele meteu suas mãos com desespero e desfez a merda como se fosse uma massa de farinha [...] (NEDICH, 2005, p.31; 95; 96; 119 - tradução nossa ). ${ }^{14}$

14 [...] Metido en la noche de su sombrero durmió junto a Carlo y el burro en el establo; los tres tenían el mismo aroma [...] / [...] Petre escupió so-
Pergunta-se se o texto de Nedich (2005) mostra a relação dos romà com o que é humano de uma forma mais natural, sem tabus ou subterfúgios, ou se ele não somente desfaz a ilusão de quem imagina os romà como encantadores, como ao mesmo tempo corrobora para a visão de que são sujos e porcos. Independentemente de ser uma coisa ou outra, acredita-se que há um "problema" nessas representações, pois em termos de estereótipos, fortalece a ideia dos não-romà de que os romà estão livres de qualquer regra, incluindo, limpeza e higiene; sendo que Gamella (2007) mostra justamente o contrário no que se refere principalmente à higiene. Segundo ele (Gamella), suas tendas são muito limpas, ainda que as condições exteriores sejam deploráveis e pouco saudáveis. O espaço interno chega a surpreender de tão limpo, ordenado, com um espaço familiar e especial sentido de dignidade humana. Fonseca (1996) ratifica esta informação ao contar que os romà deixam os arredores dos acampamentos sujos justamente para evitar que não-romà se aproximem, como uma forma de proteção e mantê-los o mais longe possível.

Mas como nunca há um acesso imediato e puro ao livro, as investigadoras dissertam sobre as suas impressões, que acompanharam as diversas leituras da obra levando em conta que a leitura maltrata obrigatoriamente o livro, adaptando-o às preocupações do leitor, que neste caso surpreenderam-se

bre su mano y le acomodó el pelo [...] / [...] mientras evacuaba su estómago, inclinó un poco el cuello hacia abajo para afinar el oído y así poder escuchar con fidelidad el sonido de sus albóndigas estrellándose contra la tierra / [...] Lucía, después de las primeras descargas, comenzó a edificar una colina de buen tamaño, entre amarilla y mostaza. [...] Stele metió sus manos con desesperación y deshizo la mierda como si fuera un grumo de harina, luego extrajo los cuatro brillantes [...] (NEDICH, 2005, p.31; 95; 96; 119). 
consigo mesmas ao darem-se conta de um instinto de proteção que emergiu ao lerem qualquer tema sobre os romà, pensando sempre em como não sustentar a "tradição" de mantê-los no lugar do preconceito e da discriminação.

Percebe-se que mais uma vez as leitoras se encaixam na teoria de Proust ao ser citado por Compagnon (2001, p.144), ao afirmar que "o leitor [..] não pode compreender um livro se não se compreende ele próprio graças" ao livro, ou seja, exatamente o que aconteceu neste momento do estudo. E então, após darem-se conta disso, as pesquisadoras voltam para o lugar de investigadoras e se perguntam: Será que tudo que Nedich (2005) descreve não é algo normal para ele e para os rom em geral? Ou será que as leitoras se traíram ao perceberem seus olhares (preconceituosos, de julgamento, ainda que positivo, com a intenção de protegê-los) quando liam determinados trechos? Acredita-se não ter neste momento uma resposta para esse questionamento.

Em todo caso, foi importante ter esta percepção ainda no momento da escrita da análise, a fim de não comprometer o estudo, e verificar que as investigadoras estavam trazendo para a análise questões que poderiam ser cruciais ao apresentarem suas expectativas a partir do que já haviam lido, dos seus repertórios, não somente sobre os rom, mas sobre tudo que os perpassa. Dessa maneira, houve tempo para reinterpretar o lido e fazer revisões contínuas, pelas quais foi possível chegar a uma significação mais totalizante desta experiência.

Assim, a narrativa se revela como parte da subjetividade do autor, implicando em uma performance do eu rom. Característica que vai ao encontro do retorno do autor e a uma das tradições mais antigas do ocidente, que é a escrita de si, a qual, conforme
Klinger, ao seguir Foucault (2004a), “não é apenas um registro do eu, mas - desde a Antiguidade clássica até hoje, passando pelo cristianismo da Idade Média - constitui o próprio sujeito, 'performa' a noção de indivíduo" (Klinger, 2012, p.22). Entendido dessa forma, ainda seguindo Foucault (1992), o "eu" não é só um assunto sobre o qual se escreve, mas uma contribuição para a formação de si, neste caso, para o processo de redefinição e afirmação da identidade étnica, como apregoa Sória (2015).

Então, pensou-se na possibilidade de que Nedich talvez não estivesse preocupado em agradar os leitores ou fortalecer uma representação romantizada e consequentemente estereotipada dos romà. Estaria ele provavelmente pensando como Marcelino Freire: "De fato, escrevo curto e, sobretudo, grosso. Escrevo com urgência. Escrevo para me vingar. E esta vingança tem pressa. Não tenho tempo para nhenhenhéns. Quero logo dizer o que quero e ir embora" (Freire, 2008a). Se é assim, Nedich poderia estar simplesmente adotando critérios implícitos, de descontinuidade do que faria um escritor contemporâneo, que na maioria das vezes desempenha um papel, preocupado em trazer em sua escrita uma possibilidade de visibilizar vozes historicamente silenciadas e a partir disso disponibilizar representações menos hegemônicas e mais plurais de compreensão dos personagens, de grupos culturais, de tempos históricos etc.

Ao acompanhar o raciocínio de Schøllhammer (2009) sobre o comentário de Freire (2008a), Nedich estaria juntando dois argumentos: o de uma escrita que tem urgência e que se impõe de alguma forma; e o de uma escrita que age para vingar-se, "como uma escrita que chega a, atinge ou alcança seu alvo com eficiência" (Schøllhammer, 2009, p.11); ou seja, sua escrita preten- 
de algo maior, ser eficaz, chegar a alcançar uma determinada realidade, a dos romà. Características que remetem à temporalidade da escrita de si nos séculos I e II, que se apresentava de duas maneiras distintas: hypomnemata e correspondência.

A primeira, em grego - significa lembrete, uma espécie de suporte material que regula a subjetividade, ou seja, seria uma maneira de formar o sujeito a partir das palavras de outros, pois estes "lembretes" são fragmentos das falas ou escritos de pessoas que ia-se anotando a medida que se acreditava importante ou que se podia levar à meditações futuras; assim estaria se formando uma subjetividade de fora para dentro e se poderia considerar como uma escrita de si pelo fato de cada um só anotar aquilo que ressoasse para si. Então, embora não fosse uma narrativa propriamente dita, levava o sujeito a refletir sobre as inúmeras questões que eram anotadas nesta espécie de caderneta e de constituir-se enquanto ser plural. Nas palavras de Foucault:

0 papel da escrita é constituir, com tudo o que a leitura constituiu, um "corpo" [...]. E, este corpo, há que entendê-lo não como um corpo de doutrina, mas sim - de acordo com a metáfora tantas vezes evocada da digestão - como o próprio corpo daquele que, ao transcrever as suas leituras, se apossou delas e fez sua a respectiva verdade: a escrita transforma a coisa vista ou ouvida "em forças e em sangue" [...] (FOUCAULT, 1992, p.133).

Estas discussões de Foucault são bastante atuais, ao lê-las pensando na literatura romaní contemporânea, que é o objeto deste estudo, pois apesar de tratar-se de uma cultura que tradicionalmente resiste à escrita, acaba por ser constituída a partir "do hibridismo cultural dos 'novos romà', representados na literatura, como a de $\mathrm{Ne}$ dich, que ressignifica a identidade étnica, no registro da memória e na autorrepresentação da voz romà expressa pelo seu próprio olhar.

Já a correspondência, “embora seja um texto por definição destinado a outro, também permite o exercício pessoal" (Klinger, 2012, p.24), porque o que é escrito e enviado "actua, em virtude do próprio gesto da escrita, sobre aquele que o envia, assim como actua, pela leitura e a releitura, sobre aquele que a recebe" (Foucault, 1992, p.134). Partindo desse pensamento pergunta-se se Nedich (1992) estaria "se valendo" da ajuda do outro, neste caso dos seus leitores, para elaborar sua própria alma, ou seja, "fazer coincidir o olhar do outro e aquele que se lança sobre si mesmo ao comparar suas ações cotidianas com as regras de uma técnica de vida" (Foucault, 1992, p.160). Modo igualmente de estar próximo aos seus, pois cada romà que lê seus livros estará em sua presença. Não apenas pelas informações que lhes dá acerca da sua vida, venturas ou infortúnios, mesmo que adornados pela ficção - mas uma presença quase física, impressa nas páginas, proporcionando "o que há de mais doce na presença: reconhecer" (Foucault, 1992, p.136). Isso se dá porque escrevendo sobre os romà, ele se mostra e faz-se aparecer junto aos outros.

Sua escrita se aproxima da "correspondência" discutida por Foucault (1992) quando relembra os efeitos do corpo, já que as notícias de saúde eram parte deste tipo de escrito, com descrições detalhadas das sensações corpóreas, como em Nedich:

Ipe sentiu que lhe chegavam as dores do reto, ficou de lado no tapete, aproveitou que o murmurinho das pessoas aumentava, se concentrou, apertou a barriga e disparou descansada e longamente um som abafado e fundo, ao que dividiu com um breve silêncio, para fortalecer um novo começo e a afi- 
nação do que parecia ser o maior de todos os peidos (NEDICH, 2005, p.141, tradução nossa $)^{15}$

Além disso, a carta era uma maneira de relatar ao correspondente sua vida quotidiana e Nedich (2005) mostra que os romà "nada tem para deixar de ser igual a todos os outros, atestando assim, não a relevância de uma atividade, mas a qualidade de um modo de ser" (Foucault, 1992, p.158); nesse caso, uma personagem se queixa de seu corpo como qualquer mulher, independente da origem, costuma fazer:

Parasquiva [...] apalpava os ínfimos peitos e lhe dizia: / - Com isto morrerei sem conquistar ninguém. / 0 mesmo opinava de suas pernas compridíssimas, de suas cadeiras estreitas. Mesmo parecendo ignorar que tinha uma escassez prometedora, tão prometedora que o menos experiente dos homens o notava [...] (NEDICH, 2005, p.171, tradução nossa). ${ }^{16}$

Aquele que escreve, de acordo com Foucault (1992), evoca o hábito de avaliar as próprias faltas e de reativar as regras de comportamento com o fito de deixar "de pecar e de trazer no coração o que quer que seja de perverso", pois ao escrever, cada um nota as ações e os movimentos da própria alma, como que dando a conhecer os fatos ao papel. Nedich (2005) corrobora com

15 Ipe sintió que le llegaban los dolores del recto, se puso de costado en la alfombra, aprovechó que el murmullo de la gente se elevaba, se concentró, apretó el vientre y disparó descansada y largamente un sonido templado y hondo, al que dividió con un breve silencio, para fortalecer un nuevo comienzo y la afinación de lo que parecía ser el mayor de todos los pedos (NEDICH, 2005, p.141).

16 Parasquiva [...] se palpaba la pobreza de sus pechos y le decía: / - Con esto moriré sin conquistar a nadie. / Lo mismo opinaba de sus piernas estrechas. Aunque parecía ignorar que tenía una escasez prometedora, tan prometedora que el más inexperto de los hombres lo notaba [...] (NEDICH, 2005, p.171).
Foucault (1992) adequando sua ideia ao contexto romà. A transformação aludida se dá ao trocar a escrita pela fala, no momento em que uma das personagens relata a uma amiga que traiu o marido e como se castigou pelo seu ato:

[...] Maida renegava a sua sorte e começou a se flagelar: retirou o véu porque o havia "manchado", depois desfez sua trança, rasgou suas saias, a blusa e se sentou sobre um formigueiro. / Dois dias depois Marta Romero lhe passava um creme para diminuir a inflamação e lhe "recomendava", para completar o tratamento, voltar à casa de Amor Caballero para buscar outra rapidinha (NEDICH, 2005, p.212, tradução nossa, no original não contêm as aspas). ${ }^{17}$

A prática de antes de deitar, repassar as obrigações, pensar sobre o dia, trazida por Foucault (1992) é mostrada em Nedich (2005) nas várias vezes que os romà aparecem "conversando" com a lua ou admirando as estrelas antes de dormir: "Ao chegar à noite, Petre foi se sentar sob as estrelas [...] / Petre, como seu pai, seu avô e todos seus antecessores, saía pelas noites pedindo favores à lua ou contando-lhe seus pesares e seus projetos" (Nedich, 2005, p.92 e 93, tradução nossa). ${ }^{18}$ Porém, fica claro que o objetivo não é fazer um exame de consciência, nem proceder a uma inspeção de si mesmo, mas tão somente desabafar e conversar com

17 [...] Maida renegaba de su suerte y comenzó a flagelarse: se quitó el pañuelo porque lo había mancillado, luego desató su trenza, desgarró sus polleras, la blusa y se sentó sobre un hormiguero. / Dos días después Marta Romero le pasaba una crema para bajarle la inflamación, le recomendó que, para completar el tratamiento, volviera a lo de Amor Caballero a buscar otro chorrito (NEDI$\mathrm{CH}, 2005, \mathrm{p} .212$ ).

$18 \mathrm{Al}$ llegar la noche, Petre fue a sentarse bajo las estrellas [...] / Petre, como su padre y su abuelo y todos sus antecesores, salía por las noches a pedirle favores a la luna o a contarle sus pesares y sus proyectos (NEDICH, 2005, p.92 y 93). 
um elemento que, para os romà, influi muito na vida dos seres humanos, e que pode ajudar ou atrapalhar o destino dos mesmos.

"O fato de muitos romances contemporâneos se voltarem sobre a própria experiência do autor não parece destoar da sociedade 'marcada pelo falar de si, pela espetacularização do sujeito'” (Klinger, 2012, p.18). No entanto, não é este o caso dos autores romà de maneira geral, pois, de acordo com Sória (2015, p.14) esta literatura fala pelos romà ao recuperar "a história grupal e apresentar a realidade do coletivo, oferecendo às sociedades circundantes uma visão de mundo, a partir da perspectiva 'de dentro'”. Ainda segundo ela, "boa parte dos escritores romà está consciente que seus textos podem contribuir na subversão dos discursos preconceituosos, desmistificar os estereótipos e estreitar os laços entre os grupos" (Sória, 2015, p.14).

Então, não se pode afirmar que a escrita de Nedich aparece como mais uma obra literária que retrata o sintoma do final do século XX (ênfase no autobiográfico), já que abarca outras questões, que estão ligadas, inclusive, a sua atuação como ativista.

Assim sendo, seus livros, e mais especificamente o analisado aqui, estão mais próximos da forma como foi construída a história da América Latina, onde a escrita de si está voltada para a formação da identidade nacional, com seus conflitos e transformações - geralmente apresentando, segundo Arfuch (2005), uma trama na qual é indiscernível o individual do coletivo; vez que os estudos atuais da cultura romà defendem a reconstrução de uma identidade grupal e ressignificação da identidade étnica.

Outra possibilidade seria afirmar que Nedich está inserido em um contexto que favorece a escrita de si, vez que na Argentina este tipo de escrita estava em alta, a pon- to de Noé Jitrik (1998), citado por Klinger (2012), afirmar que "o que chamamos de literatura argentina para o século XIX é memórias, como as do General Paz, autobiografias, como as de Sarmiento, ou diários, como os de Mansilla, por dar alguns exemplos contundentes" (Klinger, 2012, p.19). Porém, é notório que Nedich também não se encaixa nessa categoria, porque esta literatura busca "recuperar ou exaltar os valores de uma elite, de uma classe: a oligarquia [...]" funcionando "como reação contra as novas identidades emergentes, produtos da imigração" (Klinger, 2012, p.19), indo, assim, em um sentido totalmente contrário ao do autor aqui discutido.

Ao refletir sobre a escrita de Nedich pensou-se na possibilidade de ele estar atenuando a sua situação de "solidão" enquanto rom num mundo tão distante do que era ser um romà no início da sua vida. Se a suspeita estiver correta, a sua escrita corrobora com as ideias de Foucault (1992, p.129) quando afirma que "o facto de se obrigar a escrever desempenha o papel de um companheiro, ao suscitar o respeito humano e a vergonha", fazendo uma alusão ao caderno de notas para o solitário, onde podia conter "exemplos e ações de que se tinha sido testemunha [...], reflexões ou debates que se tinha ouvido ou que tivessem vindo à memória [...], constituindo uma memória material das coisas ouvidas ou pensadas" (Foucault, 1992, p. 131); mas não para simplesmente trazer à recordação algo esquecido, e sim como um material de estudo e meditação implantados na alma.

Assim, a obra de Nedich está mais próxima da interdiscursividade de Bakthin, discutida por Arfuch (2005), que assevera que o relato de experiência é a expressão de uma época, de uma classe. Nesse sentido, Nedich busca restaurar a memória coletiva 
dos romà e a sua em um só escrito, já que ele mesmo afirmou que "El aliento negro de los romaníes" é um romance que inclui ficções tiradas da sua própria vida e de seus ancestrais, bem como retrata os problemas que sua comunidade atravessa ${ }^{19}$.

Por esta razão, ao escrever estas páginas, recorda-se do pensamento de Compagnon (2001), "que mesmo a literatura mais realista não era 'operável', já que é insuficientemente precisa", havendo no "texto pontos de indeterminação como falhas, lacunas, que são reduzidas, suprimidas" pelo leitor (Compagnon, 2001, p.150) a partir de outras leituras e do olhar de um leitor real (como o texto efetivamente é lido, à sua maneira), quase sempre bem diferente do leitor ideal (o leitor implícito, abstrato, como o texto quer ser lido - o esperado pelo autor), que fatalmente é idealizado pelos escritores, como apregoava Iser ao ser citado por Compagnon (2001).

0 fato do romance em estudo se voltar para a experiência do autor pode suscitar a ideia de que Nedich estaria voltado para a tendência atual da cultura midiática, aproveitando-se desse cenário para privilegiarse ao dar visibilidade a suas histórias privadas, no entanto, acredita-se que Nedich faz parte do grupo de escritores que Silviano Santiago (2002) afirma não levar o autobiográfico para o lado da autocontemplação narcisista, servindo-se da experiência pessoal apenas como pano de fundo de problemas de ordem filosófica, social e política.

Assim, sua lógica não é a de tornar-se uma celebridade exibicionista, como acontece em alguns programas de TV que veiculam "verdadeiros espetáculos". O canal

19 Entrevista ao jornal Tiempo Argentino em 15 de julho de 2018. Disponível em: https://www. tiempoar.com.ar/nota/jorge-nedich-los-gitanos -aun-no-somos-sujetos-de-derecho.
TLC (Travel \& Living Channel), por exemplo, mostra uma série com várias temporadas do "Meu grande casamento cigano" - no original "My Big Fat American Gypsy Wedding" - que apresenta celebrações extravagantes desde a escolha do vestido da jovem noiva até a cerimônia. São apresentados como ciganos dos Estados Unidos que "seguem" as tradições, mas não dizem que tradições são essas, já que, como explicado anteriormente, a depender do grupo ao qual façam parte, as condutas mudam. Além disso, apesar de fazerem uma propaganda de que mostram os costumes romà, oferecem ao público um show de pessoas que se vestem como não -romà, mulheres que não se importam em deixar o corpo a mostra, com saias curtas e tops - não tecendo nenhum comentário a este respeito, nem sequer expondo que essas vestes poderiam ser encaradas como uma "inovação" dentro do endogrupo, já que não seria uma vestimenta comum aos romà de qualquer parte do mundo.

Os realitys passam uma imagem de que todos romà funcionam daquela forma e que "seguir a tradição" seria encomendar vestidos de mais de trinta mil reais para o casamento. E a aposta do canal não termina aí, possuem outra série intitulada "Os reis ciganos", na qual afirmam mergulhar na rotina de quatro clãs da Espanha, com livre acesso aos seus lares. Os "docu-realitys", como o TLC chama, vestem com uma nova roupagem estereótipos antigos, cujas imagens associam a uma esteticidade esperada pelas representações artísticas e literárias cristalizadas no imaginário coletivo das sociedades.

Tais programas funcionam da seguinte forma: "Acompanham" o dia a dia da jovem que fará quinze anos, mostrando, em 90\% dos casos, como não se importam com o estudo, são fúteis e não conseguem responder perguntas básicas de um concurso de beleza 
de modo inteligente, precisando ser treinadas com afinco para isso, caso queiram participar de um, como foi mostrado em um dos episódios. Em seguida, apresentam os valores dos itens da festa de quinze anos, dando destaque ao vestido, que sempre é caríssimo, nunca abaixo de 10 mil reais. Assim, os realitys apresentam os romà como pessoas muito ricas, que dilapidam o dinheiro sem critério algum e só mantêm a tradição em aspectos como grandes festas, seja de quinze anos ou casamento, regadas de muito extravagância.

Assim sendo, os próprios romà que participam deste tipo de reality shows contribuem para inscrevê-los ainda mais no lugar do inverossímil, como seres exóticos e romantizados. Tais "documentários" fazem com que alguns escritores, que tentam mostrar formas de vida e sociabilidade da maioria dos romà, que não é de extrema riqueza, como apresentado nos programas, tenham dificuldade em publicar seus livros, e isso não acontece somente nos dias de hoje, desde 1851, escritores como George Borrow já relatavam problemas em publicar romances que não representassem os romà de modo pitoresco. 0 autor conta que para publicar o romance Lavengro, que é uma mescla de memória, autobiografia e literatura de viagens quando esteve entre os romà ingleses, teve que fazer todo um trabalho de convencimento, argumentando que sua obra anterior "The Zincali", na verdade era fruto de uma imagem estereotipada, diferente do que ele propunha nesse segundo momento.

Nedich passou por situação semelhante quando enviou "El alma de los parias" para avaliadores editores. Em entrevista concedida a Sória (2015) em 16 de outubro de 2010, ele conta que:

[...] recebeu comentários de que sua obra poderia decepcionar os leitores interessa- dos em uma "história de ciganos". As alegações giravam em torno de que o romance apresentava uma realidade desgarradora, a qual não coincidia com a imagem que esperavam. Algumas respostas assinalavam que os trechos que corresponderiam a um "bom romance sobre ciganos" eram mínimos e estavam ofuscados pelas situações de miséria e exclusão, além das reflexões lúcidas do narrador sobre as questões sociais relacionadas aos romà (SÓRIA, 2015, p.151).

Ou seja, enquanto Nedich queria contar uma história mais próxima à realidade, do que realmente acontece na vida dos romà, as editoras caminham na contramão, pois elas estão preocupadas, em regra, em assuntos vendáveis, que geralmente estão calcados sob o estereótipo, não lhes interessando lançar um livro em que não representasse os romà como na maioria do tempo foi feito, envoltos em fantasias, misticismo e sensualidade, mesmo com as mudanças do contexto mundial e que os romà tenham passado por inúmeros processos adaptativos que perpassam a existência humana. Assim, é importante deixar claro que quando se fala romà está-se falando de um povo que sempre esteve em movimento e contato com vários outros povos, de culturas distintas, e que por esta razão, também foram se diferenciando nos mais diversos aspectos culturais, ainda que sua etnia seja considerada bastante fechada.

Tal diversidade não ocorre somente pela heterogeneidade dos grupos romà, mas também por todo contexto sócio-histórico-político-cultural, multiplamente construído ao longo dos discursos, práticas e posições. Ou seja, nenhum dos grupos romà pode se apresentar de maneira homogênea se a cultura não é algo estático e eles sempre estiveram em movimento e em contato com os mais diversos povos, de culturas bastante distintas entre si. Assim 
sendo, segundo Capella (2017), câmbios, transferências, sincretismos e ressignificações são inevitáveis na relação com o outro, no passar das gerações, por mais que, paradoxalmente, a etnia em questão se considere fechada.

\section{Considerações Finais}

Ao avaliar essas questões, destaca-se a importância de analisar a obra levando em conta o seu caráter de depoimento, de experiência do corpo-vivo, como diria Silviano Santiago (2002), que está por trás da escrita, e que se não for levada em consideração acaba por falsear a crítica ao romance em estudo. Silviano Santiago (2002) enriquece esta discussão ao acrescentar que esses relatos visam à conscientização do leitor, não importando tanto o aspecto literário propriamente dito.

Esse aspecto memorialístico, que no Brasil é datado nos anos 80 , está presente até os dias de hoje na Argentina, de modo que Klinger (2012) afirma que "a recuperação da memória e a luta contra o esquecimento definem boa parte das práticas culturais e literárias" de lá (Klinger, 2012, p.20), havendo uma estreita relação entre memória política e familiar, exatamente como acontece no romance "El aliento negro de los romaníes", onde se observa o cunho testemunhal do quanto os romà tiveram seus projetos de vida e valores alterados pelas circunstâncias, seja pela queima de suas barracas, seja pela mudança de nômades a sedentários, que no romance não é mostrado como obrigatório e sim como uma decisão de Petre e Maida, mas que se sabe, pelo contexto em que o romance se passa, finais dos anos quarenta, as políticas anti-ciganos estavam a pleno vapor na capital Buenos Aires, não sendo tão radicalmente efetivas no interior, que é onde se passa a história; ainda que em alguns momentos Nedich mostre um pouco desta realidade:

[...] As deixou bem a vista sobre o único móvel que tinham: um rádio, imenso como um confessionário, que não funcionava mais que em uma só estação, nela costumavam esperar incansavelmente que o informativo desse conta dos incêndios reiterados que sofriam os rom e o nome de suas vítimas e, claro, o discurso do general dizendo que seu governo não queria barracas na república [...] (NEDICH, 2005, p.157) ${ }^{20}$.

0 excerto revela que Nedich não está apenas contemplando a sua vida, mas as relações sociais que aconteceram na época que vão para além de si mesmo, percebendo-se dentro de uma coletividade que vai além dos romà, pois a postura das autoridades também influenciava negativamente na vida dos ditos sedentários, atrapalhando seus meios de sobrevivência. Desta forma, Nedich abarca uma humanidade cultural, mesmo que sua ênfase esteja nas autoindagações dos romà e na sua restauração de memória coletiva.

\section{Referências}

ARFUCH, Leonor. El espacio biográfico. Buenos Aires: Fondo de Cultura Económica, 2005.

CABAllero, J.; JOSEPHS, A. Poema del Cante Jondo y Romancero Gitano. 16. ed. Madrid: Catedra, 1995.

CAPELLA, Mikka (pseud.). Romani dromá: caminhos ciganos. $1^{\mathrm{a}}$ ed. Rio de Janeiro, RJ: Edição do autor, 2017, Edição Kindle.

COMPAGNON, Antoine. O Leitor. In: $O$ demônio

$20[\ldots]$ Las dejó bien a la vista sobre el único mueble que tenían: una radio, inmensa como un confesionario, que no funcionaba más que en una sola estación, en ella solían esperar incansablemente que el informativo diera cuenta de los incendios reiterados que sufrían los rom y el nombre de sus víctimas y, por supuesto, el discurso del general diciendo que su gobierno no quería carpas en la república [...] (NEDICH, 2005, p.157). 
da teoria: literatura e senso comum. Tradução de Cleonice Paes Barreto Mourão e Consuelo Fortes Santiago. Belo Horizonte: UFMG, 2001.

FONSECA, Isabel. Enterrem-me em pé: os ciganos e a sua jornada. Tradução. José Rubens Siqueira, - São Paulo: Companhia das Letras, 1996.

FOUCAULT, Michel. A escrita de si. In.: $O$ que é $o$ autor? FOUCAULT, Michel. Lisboa: Passagens, 1992, pp.129-160.

Sexualidade e solidão. In: MOT-

TA, M.B. (Org.). Ética, sexualidade, política. Rio de Janeiro: Forense Universitária, 2004a. p.92103.

FREIRE, Marcelino. Rasif: Mar que arrebenta. Rio de Janeiro: Record, 2008.

GAMELLA, Juan Francisco. La inmigración ignorada: Romá / gitanos de Europa oriental en España, 1991-2006. In: Gazeta de Antropología, Granada, n²3, 2007.

KLINGER, Diana. Escritas de si, escritas do outro: o retorno e a virada etnográfica. $3^{\underline{a}}$ ed. Rio de Janeiro: 7Letras, 2012.
NEDICH, Jorge. El aliento negro de los romaníes. 1a ed. Buenos Aires: Planeta, 2005.

LÓPEZ OCÓN, Mónica. Nedich: "Los gitanos aún no somos sujetos de derecho". Periódico tiempo argentino, Argentina, 15 jul. 2018. Disponível em: https://www.tiempoar.com.ar/nota/jorgenedich-los-gitanos-aun-no-somos-sujetos-dederecho. Acesso em 13 set. 2019.

SANTIAGO, Silviano. Nas malhas da letra. Rio de Janeiro: Rocco, 2002 [1988].

SCHØLLHAMMER, Karl Erik. Ficção brasileira contemporânea. Rio de Janeiro: Civilização Brasileira, 2009.

SORIA, Ana Paula Castello Branco. "Juncos ao vento": literatura e identidade romani (cigana): El alma de los parias, de Jorge Nedich. 2015. 331 f., il. Tese (Doutorado em Literatura) - Universidade de Brasília, Brasília, 2015. Disponível em: http://www.amsk.org.br/estudosepesquisa.html. Acesso em: 19 jul. 2019.

Recebido em: 03/06/2020 Aprovado em: 02/08/2020 